1 Fundação Oswaldo Cruz (Fiocruz), Escola Naciona de Saúde Pública Sergio Arouca (Ensp), Programa de Pós-graduação em Saúde Pública - Rio de Janeiro (RJ), Brasil. amanda.almentero@gmail. com

2 Fundação Oswaldo Cruz (Fiocruz), Escola Naciona de Saúde Pública Sergio Arouca (Ensp), Centro de Estudos da Saúde do Trabalhador e Ecologia Humana (Cesteh) - Rio de Janeiro (RJ), Brasil.

elidahennington@gmail.com

\section{As repercussões da Doença de Chagas no contexto de vida e trabalho de usuários de instituto de pesquisa}

\author{
The repercussions of Chagas Disease in the context of life and work of \\ users from research institute
}

Amanda Almentero Marques' ${ }^{\mathbf{1}}$ Élida Azevedo Hennington ${ }^{\mathbf{2}}$

RESUMO Este estudo buscou conhecer histórias de vida e trabalho de usuários de instituto de pesquisa, afetados pela Doença de Chagas, enfatizando o trabalho e sua relação com o adoecimento, sob a ótica desses sujeitos. Por meio da perspectiva teórico-metodológica da ergologia e do diálogo com estudos da socioantropologia sobre trabalho e experiência do adoecimento, analisaram-se as relações existentes entre trabalho e adoecimento, e suas repercussões na vida das pessoas. Concluiu-se que os sujeitos são capazes de gerir seus próprios caminhos e que não são passivos diante da prática médica.

PALAVRAS-CHAVE Doença de Chagas. Trabalho. Enfermidade. Pesquisa qualitativa. Saúde do trabalhador.

\begin{abstract}
This study aimed the knowledge of research institute users' life and work stories who were stricken by Chagas Disease, giving emphasis to the relation between work and illness under their own interpretation. Through the theoretical and methodological perspective of ergology and also with the contributions of socio-anthropological studies on work and on the experience of becoming sick, the research sought the analysis of the relationship between work and illness, and the impacts that are part of this relationship, in order to reveal these subjects' way of walking through life. It was concluded that these subjects are able to manage their own path and that they are not passive before the medical practice.
\end{abstract}

KEYWORDS Chagas Disease. Work. Disease. Qualitative research. Occupational health. 


\section{Introdução}

A Doença de Chagas produz diversas repercussões tanto na vida pessoal como na vida laboral dos indivíduos afetados. Particularmente, essa doença se caracteriza pelo estigma, por ser incurável e por ser debilitante. Outrossim, também irá provocar mudanças nas subjetividades dos afetados, em seus modos de andar a vida, levando-se em consideração a centralidade do trabalho na vida das pessoas (CANGUILHEM, 1990).

Em particular no Brasil, o programa desenvolvido pela Fundação Nacional da Saúde (Funasa) do Ministério da Saúde, a partir de 1980, foi responsável pela alta eficácia em relação ao controle da transmissão vetorial e transfusional da Doença de Chagas. O que hoje impacta o País é o atendimento desses 3 a 5 milhões de pessoas afetadas pela doença e que se coloca como questão de alta relevância para as autoridades sanitárias (GONTIJO ET AL., 2010; DIAS, 1993). Mais do que a mortalidade, a morbidade pela Doença de Chagas é preocupante pelas repercussões na capacidade de trabalho dos sujeitos acometidos.

Dias (1993) analisou o impacto da Doença de Chagas em trabalhadores em situação de busca de emprego no município de Bambuí, Minas Gerais, e concluiu que a Doença de Chagas crônica limita o trabalho e vida dos trabalhadores brasileiros, tanto na zona rural como em grandes cidades.

Guariento, Camilo e Camargo (1999) realizaram estudo com o intuito de investigar a discriminação contra o trabalhador afetado pela Doença de Chagas na cidade de Campinas. Nesse estudo puderam verificar a característica migratória dos portadores e sua baixa escolaridade. Em geral, tais trabalhadores saem das zonas rurais para buscar emprego e melhoria da qualidade de vida nos grandes centros urbanos.

Dias e Dias (1979) apontaram o processo migratório vivido por esses trabalhadores como resultado do modelo econômico do País, com uma concentração de imigrantes na periferia das grandes cidades. Os autores concluíram que existe uma grande discriminação contra os trabalhadores com Chagas no mercado de trabalho, o que resulta em piores condições de vida e consequências sociais. O diagnóstico sorológico da doença foi apontado como justificativa para a demissão, independentemente da condição clínica desses doentes, evidenciando que existe uma confusão entre uma incapacidade laboral real, que é imposta pela doença, e aquela proveniente do estigma associado à doença.

Para Uchoa et al. (2002), no âmbito do trabalho, as pessoas afetadas pela Doença de Chagas e seus empregadores acabam adotando estratégias no enfrentamento das limitações impostas pela doença. Os trabalhadores acometidos encontram mecanismos de adaptação e não consideram um problema as limitações referentes à doença, pois são facilmente contornadas pelas estratégias informais que estes encontram. Já os empregadores acabam adotando estratégias formais como aposentadoria e remanejamento, que em geral não são bem vistas pelos trabalhadores devido ao seu impacto financeiro ou discriminatório.

As pessoas afetadas pela Doença de Chagas enfrentam limitações impostas pela doença, tanto físicas como aquelas oriundas da visão da sociedade, do olhar do outro, e acabam sendo rotuladas como vulneráveis, limitados profissionalmente e vítimas da ameaça de uma possível morte súbita. A Doença de Chagas está associada a uma ideia de vulnerabilidade que pode acarretar atitudes e comportamentos de discriminação que dificultam a inserção social e profissional das pessoas acometidas (UCHÔA ET AL., 2002).

Para Alves e Souza (1999), durante o processo de busca por cuidados terapêuticos, os sujeitos fazem escolhas que são a expressão de construções subjetivas individuais e também coletivas acerca do processo de adoecimento e de formas de tratamento, moldadas de acordo com as influências de diferentes fatores e contextos. Tais escolhas 
irão definir ações que, paulatinamente, irão construir um determinado percurso.

Por outro lado, Schwartz (2007) considera que toda situação de trabalho é espaço de um problema, sendo assim, opera um uso de si, o que significa que não existe uma mera execução, mas uso, a convocação de um sujeito singular dotado de capacidades que vão além das enumeradas pela tarefa. Trabalhar significa então colocar em tensão o uso de si requerido pelos outros e o uso de si consentido e comprometido por si mesmo. Ou seja, existe o uso de si pelos outros, mas também o uso de si por si, pois não existe apenas um 'enquadramento', um controle, ocorre autogestão e microgestão do trabalho (DURRIVE; SCHWARTZ, 2008).

No caso das pessoas acometidas pela Doença de Chagas, é preciso elucidar os caminhos em busca de diagnóstico e tratamento, bem como as estratégias adotadas no enfrentamento da doença na vida e no trabalho.

Este artigo é resultante da dissertação de mestrado apresentada à Escola Nacional de Saúde Pública Sergio Arouca intitulada 'Histórias de vida e trabalho de usuários de instituto de pesquisa: o caso das pessoas afetadas pela Doença de Chagas', aprovada em julho de 2015. Durante a realização da pesquisa de mestrado, a pesquisadora obteve uma bolsa Capes (Coordenação de Aperfeiçoamento de Pessoal de Nível Superior). A pesquisa teve como objetivos: conhecer e analisar histórias de vida e trabalho de usuários de um instituto de pesquisa, com ênfase na experiência do adoecimento e sua relação com o trabalho.

O projeto deste estudo foi avaliado e aprovado pelo Comitê de Ética e Pesquisa com Seres Humanos do Instituto Nacional de Infectologia (INI/Fiocruz), sob $\mathrm{n}^{\mathrm{o}} 1.162 .574$ de acordo com a Resolução no 466/2012 do Conselho Nacional de Saúde.

Esta pesquisa possui como pressuposto o fato de considerar que usuários de instituição que agrega atividades de pesquisa, ensino e assistência vivenciam e experimentam uma trajetória singular a partir de seu adoecimento e integração a um ambiente científico e de cuidado. Outro pressuposto da pesquisa é que o adoecimento provoca importantes repercussões na vida das pessoas, principalmente em relação à vida laboral, aos sentidos do viver e no desenvolvimento de atividades de trabalho remunerado e não remunerado, necessários à subsistência e reprodução dos sujeitos na sociedade.

A discussão do adoecimento pela Doença de Chagas e suas repercussões físicas e psíquicas e sua vinculação ao mundo do trabalho evidenciam seu caráter negligenciado, a incapacidade e limitações que ela pode gerar nos sujeitos acometidos, assim como o estigma e discriminação causados por ela. Tal estudo possui como característica a originalidade de estar situado em instituto de pesquisa, o que denota um caráter particular relativo à trajetória desses usuários que são ao mesmo tempo pacientes e sujeitos de pesquisa.

\section{Métodos}

O estudo foi realizado no Instituto Nacional de Infectologia (INI), da Fundação Oswaldo Cruz (Fiocruz), no campus de Manguinhos na cidade do Rio de Janeiro. Os sujeitos de pesquisa deste estudo foram selecionados a partir do laboratório de Doença de Chagas (LapclinChagas) do Instituto. Foram selecionados oito sujeitos de ambos os sexos, em acompanhamento com no mínimo um ano na instituição, selecionados a partir da indicação dos médicos assistentes. Foram excluídos pacientes com menos de um ano de acompanhamento, com quadro agudo ou grave, incapacitados para fornecer informações ou que se recusaram a participar do estudo. Para tal seleção, foi solicitado aos médicos assistentes que indicassem pacientes já com um histórico e vínculos fortalecidos dentro da instituição, para que assim pudessem fornecer entrevistas mais ricas em conteúdo em relação à sua vivência da doença e trajetória na instituição. 
Para a discussão do conceito de trabalho como parte central da vida dos sujeitos entrevistados, as discussões propostas pelo referencial ergológico desenvolvido pelo filósofo francês Yves Schwartz, em conjunto com seus colaboradores, foram usadas como base. Assim, a base metodológica foi construída por meio do diálogo da ergologia com estudos da socioantropologia sobre trabalho e experiência do adoecimento.

Os sujeitos selecionados foram entrevistados individualmente a partir de roteiro proposto. Além das entrevistas, foram analisados prontuários de todos os pacientes selecionados com o intuito de identificar características da doença, quadro clínico, evolução, procedimentos médicos realizados e relatos da equipe multiprofissional, entre outras informações, a fim de conhecer a trajetória dos usuários no interior da instituição e com o objetivo de complementar, elucidar e corroborar dados das entrevistas. Foi elaborado diário de campo como registro de todos os acontecimentos referentes à trajetória da pesquisadora no desenvolvimento do trabalho de campo.

Trata-se de um estudo qualitativo em que foi utilizada a análise temática como ferramenta para o tratamento e análise dos dados obtidos através de entrevistas. Os dados foram produzidos com base nas narrativas dos sujeitos, de sua vivência e experiência com foco a partir do adoecimento e sua busca por cuidado. Foram realizadas entrevistas semiestruturadas, seguindo um roteiro temático previamente elaborado com algumas questões, com o intuito de orientar o pesquisador.

Para a execução da análise temática proposta por Deslandes (2001), foi utilizado o modelo proposto por Oliveira (2008), que traz um processo de sistematização da análise de conteúdo temático-categorial. Segundo tal modelo, tais procedimentos, suas etapas e os instrumentos utilizados para apoiar tal desenvolvimento são sintetizados assim: primeiramente é realizada a leitura flutuante, ou seja, é realizada uma leitura exaustiva de todo o texto da entrevista para que o pesquisador seja impregnado pelos conteúdos ali presentes.

Foram analisadas 8 entrevistas, sendo identificadas 134 URs (Unidades de Registro), distribuídas em duas categorias analíticas definidas a priori: 'histórias de vida e trabalho' e 'modos de andar a vida e experiência do adoecimento e busca por cuidado: os usos de si'. Para facilitar a visualização e a distribuição das URs nas categorias, os dados estão organizados em tabelas simples, com frequência absoluta, conforme proposto por Oliveira (2008), o que facilitou a apresentação e análise dos dados que emergiram das entrevistas. Seguem as tabelas sínteses:

Tabela 1. Síntese das unidades de registro e unidades de significação na análise de conteúdo

\begin{tabular}{|c|c|c|c|c|c|c|c|c|c|c|c|}
\hline 1 & 2 & & & & & & & & & 4 & 5 \\
\hline \multirow{3}{*}{$\begin{array}{l}\text { Código do } \\
\text { Tema }\end{array}$} & \multirow{3}{*}{ Temas/Unidades de Significação } & \multicolumn{9}{|c|}{ Número de Unidades de Registro (UR) } & \multirow{3}{*}{$\begin{array}{r}\text { № Total Corpus } \\
\text { Analisados }\end{array}$} \\
\hline & & \multirow[b]{2}{*}{01} & \multirow[b]{2}{*}{02} & \multirow[b]{2}{*}{03} & \multirow[b]{2}{*}{04} & \multirow[b]{2}{*}{05} & \multirow[b]{2}{*}{06} & \multicolumn{2}{|c|}{ CORPUS } & \multirow[t]{2}{*}{ Total UR } & \\
\hline & & & & & & & & 07 & 08 & & \\
\hline R1 & Repercussões do afastamento do trabalho & 3 & 5 & 2 & 10 & 8 & 7 & 15 & 2 & 52 & 8 \\
\hline E2 & Itinerário terapêutico e enfermidade & 9 & 13 & 10 & 14 & 0 & 10 & 18 & 8 & 82 & 8 \\
\hline TOTAL UR & & 12 & 18 & 12 & 24 & 8 & 17 & 33 & 10 & 134 & 16 \\
\hline
\end{tabular}

Fonte: Oliveira (2008).

Nota: Identificação da pesquisa 'Histórias de vida e trabalho de usuários de instituto de pesquisa: o caso das pessoas afetadas pela doença de Chagas', ํo páginas analisadas: 128 
Tabela 2. Síntese da construção de categorias na análise de conteúdo

\begin{tabular}{|c|c|c|c|c|c|c|}
\hline 1 & 2 & 3 & 4 & 5 & 6 & 7 \\
\hline $\begin{array}{l}\text { Temas/ Unidades de } \\
\text { Significação }\end{array}$ & № UR/ Tema & \% UR/ Tema & Categorias & № UR/ Categoria & \% UR/ Categoria & Observações \\
\hline $\begin{array}{l}\text { Repercussões do afas- } \\
\text { tamento do trabalho }\end{array}$ & 52 & 38,8 & $\begin{array}{r}\text { História de vida e trabalho e os } \\
\text { modos de andar a vida }\end{array}$ & 52 & 38,8 & \\
\hline $\begin{array}{l}\text { Itinerário terapêutico e } \\
\text { enfermidade }\end{array}$ & 82 & 61,2 & $\begin{array}{l}\text { Experiência do adoecimento e } \\
\text { busca por cuidado: os usos de si }\end{array}$ & 38 & 61,2 & \\
\hline TOTAL UR & 134 & 100 & & 134 & 100 & \\
\hline
\end{tabular}

Fonte: Oliveira (2008).

Nota: Identificação da pesquisa 'Histórias de vida e trabalho de usuários de instituto de pesquisa: o caso das pessoas afetadas pela doença de Chagas', no páginas analisadas: 128.

\section{Resultados e discussão}

Foi possível notar como os sujeitos relatam sua busca por cuidado, muito baseada naquilo que sua rede de contatos, tanto familiar como social em geral, colocam para ele como importante. A própria definição de doença é construída tendo como peça fundamental essa apropriação dos conceitos trazidos por essa rede humana existente à sua volta. No caso específico da Doença de Chagas, a rede de apoio familiar trouxe grande contribuição para a forma como o cuidado foi buscado, já que a doença geralmente acomete mais sujeitos de uma mesma família, pois muitos são oriundos das áreas consideradas endêmicas. Observou-se que já existia, para esses sujeitos, um conhecimento prévio sobre a doença, conhecimento que ele recebe dentro do meio familiar e que o orienta na busca de cuidado.

As seguintes URs podem demonstrar tais afirmações:

Não, não, não, quando eu já tinha pensamento por causa do meu irmão como você falou, que ele tinha Doença de Chagas, e ele: faz esse exame, faz esse exame, aí eu procurei o médico aí, em Caxias, aí passou lá e eu vim fazer aqui, aí eu fiquei tomando remédio da Doença de Chagas, aí a coisa é pouca né. (Entrevistado 3).

Eu já tinha visto falar porque a minha ex-sogra ela morreu desse problema. (Entrevistado 1).

Quatro pessoas, da minha família né, agora primo. Morreu minha sogra, minha mãe, meu pai. (Entrevistado 2).

Porque a minha mulher se tratava aqui aí eu vim pra cá. (Entrevistado 2).

Aí eu cheguei, fui em Caxias, em vários hospitais lá, pedi pra fazer e disseram que no Caxias não fazia e eu fui descobrir porque tenho parente que tem Doença de Chagas e eu vou ver se eu... aí eu vim, me ensinaram aqui me explicaram aqui e eu vim pra aqui e aí eu fiz. (Entrevistado 3).

As URs mostradas acima demonstram como a Doença de Chagas possui um forte aspecto familiar e como a percepção dos sintomas, em um primeiro momento, foi feita com base naquilo que outros sujeitos da família já haviam vivenciado, orientando, assim, um segundo momento, a busca por diagnóstico e tratamento. A UR 4 é de um sujeito cuja esposa também possui a doença, e ambos são tratados no INI.

Os entrevistados, de modo geral, referiram o bom atendimento prestado no instituto e a boa relação estabelecida especialmente com a equipe médica. Na quarta entrevista, pode-se observar o conflito existente entre diferentes modelos explicativos para a Doença de Chagas, pois esse sujeito 
é atendido no INI ao mesmo tempo que recorre à prática espiritual. Esse conflito pode ser percebido na seguinte UR a partir do uso de medicamentos prescritos pelo médium:

Não, essas coisas eu não comento. Não comento porque eu não sei se o dr. [...], se ele aceita a doutrina espírita ou não, aí eu prefiro não comentar. E queria ressaltar também, já que tá aí né, que ele me passou dois remédios... dois remédios não, três, para a próstata. Eu tomo um, pra próstata, e outro chamado, esse também é da próstata, e um remédio pra [...]. E é isso que eu tomo. (Entrevistado 4).

Sendo assim, pode se observar que o sujeito 'paciente' não adota uma atitude passiva diante da prática médica. Ele possui saber próprio, sendo capaz de buscar alternativas próprias e caminhos diferentes daqueles preconizados pela prática médica tradicional. Ele optou por manter dois tipos de tratamento, o formal, biomédico e o popular ou complementar. Como as práticas complementares/populares ainda não são totalmente aceitas pelo meio científico hegemônico, persiste uma incapacidade de dialogar com modelos explicativos de doença diferentes. O sujeito-paciente inclusive não se sentiu à vontade para declarar ao médico assistente o fato de realizar também acompanhamento 'espiritual'.

O sexto entrevistado relata como o tratamento reestruturou sua forma de andar a vida, criando uma rotina de disciplina que gerou uma melhoria, como se fosse um ganho, já que, no passado, sua vida encontrava-se desestruturada pela 'falta de ordenamento e sentido'. Evidenciou um sentido positivo da doença e do tratamento como geradores de estrutura para vida do sujeito.

É. Porque tudo tem que ter horário agora, antigamente não tinha horário pra nada. Agora eu tenho horário. Horário de tomar remédio, horário de comer, horário. Eu antigamente não tinha nada disso. (Entrevistado 6).
Outro aspecto importante existente dentro de um processo de itinerário terapêutico é o fato de que os significados atribuídos pelo sujeito sobre sua própria doença podem não corresponder aos significados do médico, o que o leva a ações de negação ou ambivalência. Quando ocorre um caso de discrepância entre as construções do processo saúde-doença entre paciente e médico, o paciente encontra então dificuldades em decidir se adere ou não à proposta do tratamento (MONIZ; BARROS, 2005). Na sétima entrevista, o sujeito demonstra não acreditar que a informação médica passada sobre a contaminação esteja correta:

Quando eu internei, eu fiquei em uma maca lá, internado, não sei o quê... eu falei 'Dra. eu já fui atleta de alto rendimento, cara; não era pra eu tá aqui não'. (Entrevistado 7).

Essa doença, normalmente, ela é passada através de um... de um inseto. Você não escolhe onde você vai estar. (?) Criança talvez... quando eu era criança. Não partiu de mim. Então, é difícil pra gente aceitar uma coisa quando não parte da gente. É difícil. Há quem diga que é mais difícil ainda você aceitar quando parte de você mesmo, 'Ah, não sei o quê....'. (Entrevistado 7).

As URs descritas acima se tratam do caso do sujeito que demonstra em suas falas a sua dificuldade em aceitar a doença, pois relata que "não fez nada" para isso, já que também não acredita que tenha sido contaminado na infância, como foi dito pelo médico. Ele considera que não fez nada para que essa situação de doença ocorresse, então encontra dificuldades em aceitar a verdade médica.

A entrevista cinco é o caso de um sujeito que encontra na religião e nas atividades da igreja uma forma de manter-se ativo. A sua narrativa é marcada pela forte dimensão que este papel desempenhado na igreja ocupa hoje em sua vida e a crença de que manter-se 'ocupado' faz com que outros males e até mesmo a morte sejam afastados. 
Mestre da vinha porque eu me dedico muito à obra de igreja na comunidade, da minha religião. (Entrevistado 5).

Eu trabalho muito em casa, aqui ali, lavo o quintal aquilo tudo. E gosto, olha eu gosto de trabaIhar, porque se você tiver a oportunidade um dia de se aposentar minha filha não para não, porque a mente parou, você parou a mente parou, o que governa corpo é a mente, não sei se você sabe disso, a mente que governa o corpo, se você minha filha for pensando em besteira, for pensando na morte da bezerra vai morrer logo, logo, é isso aí... (Entrevistado 5).

Os entrevistados, em sua maioria, exceto um, foram afastados de seu trabalho formal devido à doença. A sétima entrevista é marcada pelo medo de o sujeito ser considerado incapaz de realizar seu trabalho e interromper seus sonhos de progressão na carreira militar.

Dessa maneira, observa-se, no percorrer das narrativas, que a Doença de Chagas opera mudanças radicais no contexto de vida e de trabalho desses sujeitos, mas que, diante desse novo panorama em que se encontram, buscam novas formas de enfrentamento das condições impostas pela nova situação causada a partir da doença. Para Schwartz e Durrive (2008), as mudanças na forma de ser e fazer o trabalho resultam na confrontação com o novo, e também com os diferentes tipos de problemas que precisam ser solucionados, a partir dessa nova dinâmica que se apresenta.

De acordo com tal perspectiva, torna-se clara toda a capacidade e potencial do sujeito que surgem neste novo contexto no qual se vê inserido, pois a confrontação com o novo vai operar mudanças nesse sentido. O sujeito em confronto com o novo mostra então toda sua potencialidade ao implementar novas maneiras de operar a sua realidade, entendendo-se o trabalho como espaço de constantes microtransgressões e rupturas, e de criar novas entidades coletivas (HENNINGTON, 2008).
A atividade de trabalho em si caracteriza-se por um certo grau de imprevisibilidade, e é impossível listar completamente o que a constitui e, desta maneira, manifesta-se a chamada infidelidade do meio. De acordo com Schwartz (2007, P. 191), "o meio é sempre mais ou menos infiel, ele jamais se repete exatamente de um dia para outro ou de uma situação para outra".

Os sujeitos entrevistados vivenciavam situações que não gostariam de estar, pois a doença é capaz de impor uma nova condição de vida e trabalho. $\mathrm{O}$ afastamento obrigatório do trabalho, por vezes, gera uma insatisfação, tendo em vista o caráter central que o trabalho ocupa na vida desses sujeitos. Como pode ser observado nas seguintes URs:

Toda e qualquer forma produtiva. Pra mim, o meu trabalho é a minha vida. É a minha vida. (Entrevistado 1).

Pra mim o trabalho é tudo né, porque o dia que não tiver isso pra mim é parece que o mundo acabava e eu tinha aquele costume, todo dia levantava 4 horas, muito difícil. (Entrevistado 2).

O trabalho é pra você, o meu trabalho era o que, pra mim é exercício pra você não ficar parado. (Entrevistado 6).

Fiquei triste, porque a gente trabalha desde pequeno né, como eu já falei, então você parar, tem que ficar dentro de casa, sem ter o que fazer. (Entrevistado 2).

Schwartz e Durrive (2008) consideram que o emprego, na nossa sociedade atual capitalista, caracteriza-se como uma modalidade particular em que o trabalho é enquadrado às pessoas.

Essa caracterização feita pelos autores de enquadrar o trabalho pode ser compreendida como um controle que é feito do trabalho dos sujeitos por parte dos que possuem a gestão e o poder dentro das empresas. Tal lógica mercantil provoca um empobrecimento da 
compreensão do que é trabalho/atividade e sua relevância na vida das pessoas.

Foi evidente nas entrevistas analisadas, porém, que por mais endurecido que seja esse trabalho mercantil, ele é capaz de produzir um ordenamento para o sujeito, que se sente pertencente a uma comunidade de trabalho e a um modo de estar na vida.

Foi recorrente também nas entrevistas analisadas que os sujeitos são expostos a diferentes e diversas infidelidades, pois sua nova situação de trabalho, muitas vezes informal e doméstica, como também sua nova condição física e demais restrições impõem tal condição. Tais condições adversas acabam conduzindo esses sujeitos no caminho de utilizar seus recursos e capacidades, e também suas escolhas conscientes e inconscientes para o enfrentamento de tais infidelidades. Sendo assim, percebe-se que a atividade de trabalho é capaz de incorporar diversos contornos, em que o trabalho surge como espaço fluido que permite fazer de outra forma, espaço no qual ocorrem as renormatizações (SCHWARTZ, 2007).

Por serem impedidos de trabalhar formalmente, os sujeitos são levados a encontrar novas formas de atividade, ou também formas de continuar no seu trabalho formal, a partir de renormatizações, com o intuito de continuar a trabalhar e adaptar- se a sua nova condição de saúde.

Eu ajudo ela, eu arrumo, eu arrumo casa, varro quintal, limpo a bomba pra ela encher água da caixa. (Entrevistado 6).

Ela me orientou, explicou o que poderia acontecer e eu analisei, julguei e vi que aquilo eu não posso mais fazer por conta da minha deficiência física. Deficiência não; incapacidade física. Mas também eu falei pra ela 'mas eu vou crescendo, cara'. Eu sou o piloto. Hoje eu começo com 1 km, amanhã com $1 \mathrm{~km}$ e $100 \mathrm{~m}$, depois 200 e assim eu vou embora. Quando eu for ver, tô com uns $3 \mathrm{~km}$ e $200 \mathrm{~m}$ de novo. [Trata-se de um militar ainda na ativa, que apesar da doença e das recomendações médicas, continuou fazendo exercícios físicos no intuito de voltar a realizar as atividades físicas a que estava acostumado]. (Entrevistado7).

Durante o percurso das narrativas, conseguiu-se analisar que o sujeito 'paciente' não possui uma característica passiva. $\mathrm{Na}$ verdade, ele faz usos de si no trabalho e na vida e é capaz de buscar alternativas próprias ao seu tratamento. Também é detentor de um conhecimento sobre a sua doença, conhecimento este originado do seu contexto familiar e social. Muitas vezes o tratamento médico tradicional sozinho mostra-se incapaz de responder aos anseios e crenças desses sujeitos, que buscam novos caminhos, que podem ser tratamentos espirituais, práticas religiosas etc., que seguem em concomitância e complementares à prática médica tradicional.

\section{Considerações finais}

Observou-se, neste estudo, que a doença alterou de maneira significativa o modo de andar a vida por parte dos sujeitos acometidos. Houve o estigma e o medo de ser considerado um trabalhador 'incapaz', a negação, a dificuldade de encarar e de aceitar o diagnóstico, a valorização da relação e da confiança na equipe de saúde entremeados por atos de rebeldia e o comportamento não passivo diante do saber e da prática médica. Demonstrou o quanto muitas vezes é difícil o diálogo entre as crenças, valores e aspirações dos pacientes/usuários e aquilo que é preconizado pelo modelo biomédico hegemônico. Também desencadeou a busca de novos caminhos e maneiras inovadoras de encarar a vida e o trabalho.

Devido ao caráter limitado da população estudada, verifica-se a necessidade de desenvolvimento de novos estudos com o intuito de ampliar o conhecimento e o debate em relação à Doença de Chagas e suas 
correlações com a vida e o trabalho.

Como foi analisado, a Doença de Chagas é capaz de gerar repercussões importantes na vida dos indivíduos acometidos, podendo evoluir para o óbito, quadros incapacitantes ou não. Muitas vezes essas repercussões referem-se mais a aspectos psicológicos do que a físicos, já que, em diversas situações, a doença tem como característica ser estacionária, assintomática ou com sintomas controlados. Sendo assim, os trabalhadores podem se sentir bem e em condições de realizarem suas tarefas no trabalho, e somente quando se deparam com a situação de afastamento, realmente sentem a doença de maneira negativa e com um impacto emocional forte, constituindo-se como uma verdadeira dramática.

A trajetória que esses sujeitos constroem ao longo de seu itinerário terapêutico é repleta de sentidos. Assim, deve-se levar em conta todo cenário cultural no qual estão inseridos, pois é por meio de tais processos sociais que os sujeitos irão legitimar suas experiências de doença e poderão atribuir sentido a elas. Ou seja, o todo social no qual estão inseridos é de extrema importância para a compreensão desse processo de enfrentamento da doença que vivenciam. No caso dos portadores de Doença de Chagas, a família forneceu a eles todo um aparato simbólico que os ajudou a construir a sua concepção da doença e orientou a busca de cuidado.

Apesar do impacto emocional causado pelo diagnóstico, observou-se então que cada sujeito possui uma forma singular de lidar com a doença e com o tratamento, assim como com o impacto ocasionado pela descoberta da Doença de Chagas em suas vidas. Muitos deles mostraram que as estratégias de enfrentamento encontradas, sejam elas a religião, a fé, novas práticas de trabalho, nova ocupação e o próprio tratamento, os guiam para manter uma rotina de vida marcada por um impulso positivo e de vida. Impulso também gerado pela confiança que narraram ter encontrado atendimento prestado no INI. Ou seja, o paciente se mostra realmente sujeito. É capaz de reconhecer a importância e os benefícios de uma boa atenção à saúde, mas também é capaz de julgar o que lhe é mais conveniente e traçar seus próprios caminhos. Está longe de ser uma figura passiva em sua trajetória de tratamento, busca por cuidado e enfrentamento da doença. Muitos encontraram estratégias positivas que os ajudaram a continuar ativos e produtivos, além de complementar sua renda. O que evidenciou que o trabalho, apesar de ganhar novos contornos e renormatizações, continua desempenhando um papel central em suas vidas.

\section{Colaboradores}

Amanda Almentero Marques - autora principal. Élida Azevedo Hennington - coautora.

\section{Agradecimentos}

Agradecemos ao Dr. Alejandro Moreno Hasslocher e à equipe do Laboratório de Pesquisa Clínica em Doença de Chagas do Instituto Nacional de Infectologia pela inestimável colaboração no desenvolvimento da pesquisa.

Agradecemos a imprescindível participação das pesquisadoras Ana Rosali Louvize Gomes da Silva e Kim Geraldo na realização do trabalho de campo. 


\section{Referências}

ALVES. P. C. B.; SOUZA, I. M. Escolha e avaliação de tratamento para problemas de saúde: considerações sobre o itinerário terapêutico. In: RABELO, M. C.; ALVES, P. C. B.; SOUZA, I. M. A. (Org.). Experiência de doença e narrativa. Rio de Janeiro: Fiocruz, 1999.

CANGUILHEM, G. O Normal e o patológico. 3. ed. rev. e aum. Rio de Janeiro: Forense Universitária, 1990.

DESLANDES, S. F. (Org.). Pesquisa social: teoria, método e criatividade. Petrópolis: Vozes, 2001.

DIAS, J. C. P. Aspectos clínicos, sociais e trabalhistas da doença de Chagas em área endêmica sob controle do Estado de Minas Gerais, Brasil. Revista da Sociedade Brasileira de Medicina Tropical, Uberaba, v. 26, n. 2, abr./jun. 1993. Disponível em: <http:// www.scielo.br/scielo.php?script=sci_arttext\&pid $=$ S0037-86821993000200005 $>$. Acesso em: 8 abr. 2016.

DIAS, J. C. P.; DIAS, R. B. Aspectos sociais da Doença de Chagas. Revista Goiana de Medicina, Goiânia, v. 25, p. $257-268,1979$

DURRIVE, L.; SCHWARTZ, Y. Glossário da Ergologia. Laboreal, Porto, v. 4, n. 1, p. 23-28, jul. 2008. Disponível em: $<$ http://laboreal.up.pt/pt/articles/glossario-da-ergologia/>. Acesso em: 8 abr. 2016.

GONTIJO, E. D. et al. Qualidade de vida dos portadores de Doença de Chagas. Revista Médica de Minas Gerais, Belo Horizonte, v. 19, n. 4, out./dez. 2009. Disponível em: <http://bases.bireme.br/cgi-bin/wxislind.exe/iah/ online/?IsisScript=iah/iah.xis\&src=google\&base=LILA CS\&lang $=$ p\&nextAction $=\operatorname{lnk} \&$ exprSearch $=546404 \&$ ind exSearch=ID>. Acesso em: 8 abr. 2016.

GUARIENTO, M. E.; CAMILO, M. V. F.; CAMARGO,

A. M. A. Working conditions of Chagas' disease patients in a large Brazilian city. Cadernos de Saúde Pública, Rio de Janeiro, v. 15, n. 2, abr. 1999. Disponível em: $<$ http://repositorio.unicamp.br/bitstream/
REPOSIP/101210/1/2-s2.0-0033107248.pdf>. Acesso em: 8 abr. 2016

HENNINGTON, E. A. Gestão dos processos de trabalho e humanização em saúde: reflexões a partir da ergologia. Revista Saúde Pública, São Paulo, v. 42, n. 3, p. 555-561, 2008. Disponível em: <http://www.scielo. br/pdf/rsp/v42n3/6707.pdf>. Acesso em: 8 abr. 2016.

MONIZ, L. J.; BARROS, L. Psicologia da doença para cuidados de saúde: desenvolvimento e intervenção. Porto: Edições Asa, 2005.

OLIVEIRA, D. C. Análise de conteúdo temático-categorial: uma proposta de sistematização. Revista de Enfermagem da UERJ, Rio de Janeiro, v. 16, n. 4, p. 569-576, 2008. Disponível em: <http://www.scielo.br/ scielo.php?script=sci_nlinks\&ref=000125\&pid=S1413$-7372201400020000300018 \& \operatorname{lng}=p t>$. Acesso em: 8 abr. 2016.

SCHWARTZ, Y. Trabalho e ergologia. In: SCHWARTZ, Y.; DURRIVE, L. (Org.). Trabalho e ergologia: conversas sobre a atividade humana. Niterói: Eduff, 2007.

SCHWARTZ, Y.; DURRIVE, L. Revisitar a atividade humana para colocar as questões do desenvolvimento: projeto de uma sinergia franco-lusófona. Laboreal, Porto, v. 4, n. 2, p. 19-22, 2008. Disponível em: <http:// laboreal.up.pt/files/editions/2008_07/laboreal_2008_07_pt.pdf>. Acesso em: 8 abr. 2016.

UCHÔA, E. et al. Signos, significados e ações associados à doença de Chagas. Cadernos de Saúde Pública, Rio de Janeiro, v. 18, n. 1, p.71-79, 2002. Disponível em: <http://www.scielo.br/pdf/csp/v18nl/8144.pdf>. Acesso em: 8 abr. 2016

Recebido para publicação em agosto de 2016

Versão final em janeiro de 2017

Conflito de interesses: inexistente

Suporte financeiro: não houve 